reflecting telescope of Isaac Newton, a full-sized model of Hooke and Boyle's pneumatic engine or air-pump, Sutton's 16-inch planisphere, quadrants, and the adding machine invented by Sir Samuel Morland and presented to Charles II. in 1666, from the Lewis Evans Collection in the Old Ashmolean at Oxford. Viscount Knutsford is showing his interesting screwbarrel microscope and 6-foot vellum-draw telescope by William Longland. The Royal Society has sent portraits of Sir Isaac Newton, Pepys, Evelyn, and Wren. Further attractive features are the fine clocks and watches made by Edward East with his apprentice Henry Jones, Fromanteel, Robert Seignoir, and Joseph Knibb. The medical and surgical practice of the time is rather inadequately represented by a barber-surgeon's bowl and several drug-pots, but Capt. Collins's "Coasting Pilot", exhibited by the Lords of the Admiralty, reminds us that the first hydrographic survey of the British Isles was also a product of the reign of Charles II. The exhibits are well arranged, and, not being crowded, can be well seen.

\section{New Pyramid at Giza}

THe discovery of a fourth pyramid at Giza, as reported in the Times of Feb. 18 and subsequent issues, is likely to provide Egyptologists with a historical puzzle, as well as presenting some peculiar and interesting features in itself. The method of construction would appear to be unusual, for it is said that the southern face, which looks on the valley and is much weathered, is cut out of the sandstone. Another remarkable feature is the enormous granite slabs lining the passage which leads to the interior of the pyramid, and equally interesting are the two windows facing east, which open from the entrance chamber. These, it is suggested, may be connected with the enhanced influence of sun-worship usually attributed to the fifth dynasty. The most striking feature, however, is the fact that the names and titles of the owner of the large chamber cut out of the rock on the south-east of the pyramid show that it belonged to Queen Khent Kawes, " King of Lower and Upper Egypt". The name is not enclosed in the usual cartouche, but is ensigned with a royal uræus. This title is not known to have been applied to any other queen of the Old Kingdom. The official communique suggests that, while not the actual ruler of Egypt, she may have been regent during her son's minority. It goes on to point out that it is possible that she may have been connected by birth with the fourth dynasty; but that otherwise it is singular that a pyramid should have been erected for her at Giza at the time of the fifth dynasty, which resided at Abusir.

\section{Gallium, a Commercial Product}

ALthough the presence of the metal gallium has been detected in a great variety of minerals, it occurs in such minute amount even in zincblende, which is its chief source, and its isolation is so laborious, that until quite recently only very small quantities were available. The Chemiker-Zeitung for Jan. 2 announces that the Vereinigte Chemische Fabriken at Leopold schall, Stassfurt, manufacturers of the rare element rhenium, have succeeded, after lengthy experimental trials, in isolating gallium by a method which enables them to produce the metal at one-twentieth of its former cost, which a year ago stood at about 175 gold marks per gram. Thus the way to the commercial development of this remarkable metal is at last opened.

CoNSIDERABLE attention has already been given to the properties of gallium, chiefly on account of the long thermal range of stability of its liquid phase. Thus the pure metal melts at about $30^{\circ} \mathrm{C}$. and boils at a temperature above $2000^{\circ} \mathrm{C}$. It has therefore been used for filling quartz thermometers for registering temperatures above $500^{\circ}$ C. Some of these have already been sent to the Physikalisch-Technische Reichsanstalt for standardisation. Gallium can also be used to replace mercury in vapour arc-lamps for use in analytical work. Indeed, its application in this direction should lead to important results, on account of the wide range in frequency in the lines of its spectrum, which extend from the ultra-violet to well into the red region. It has also been used in the form of alloys with other metals to replace the dental amalgams, which are said to have produced some harmful results. Satisfactory results from gallium alloys have been reported. Gallium and some of its alloys can also be used for the production of special optical mirrors, and no doubt many other applications will be found now that the metal has become an article of commerce.

\section{Earth Pressures}

AT the Friday evening discourse at the Royal Institution on Feb. 19, Prof. C. F. Jenkin discussed the mechanics of shifting sand. Prof. Jenkin explained why experiments intended to measure the pressure exerted by granular material, such as sand, fail, and showed that the failure is due to arching, a necessary consequence of the property of dilatancy, discovered by Osborn Reynolds. The latest design of apparatus for measuring the forces on a retaining wall was shown, and the results of a test made with it were described. With this apparatus the old earth pressure theories have been tested and the truth in them separated from the error. As a result, a revised. wedge theory has been formulated. The apparatus was shown to be capable of measuring the forces not only on plane walls, of any batter, but also on stepped walls and on L-shaped walls, and also of measuring the forces under water. Finally, by an ingenious device, a wall of sand has been tested and the true friction angle between two sand faces measured. The reaction, that is, the force exerted by the wall on the sand, was described and its importance illustrated by an account of the partial failure of a great weir in Australia. The apparatus described can only deal with one-quarter of the whole problem of earth pressures; it cannot measure the forces under a foundation, and it cannot measure either horizontal or vertical forces exerted by clay.

\section{International Co-ordination of Locust Research}

Some time ago the Imperial Institute of Entomology in London organised, with the financial support of the

No. 3252, VoL. 129] 